\title{
The decline of the Chinese giant salamander Andrias davidianus and implications for its conservation
}

\author{
Xiao-ming Wang, Ke-jia Zhang, Zheng-huan Wang, You-zhong Ding, Wei Wu and Song Huang
}

\begin{abstract}
The Chinese giant salamander Andrias davidianus is the largest living amphibian. Most wild populations are threatened and some are already extinct. The Chinese government has declared the species a Class II Protected Species, and it is listed as Critically Endangered in the Chinese Red Book of Amphibians and Reptiles and as Data Deficient on the IUCN Red List. Populations of the species have declined sharply in both range and number since the 1950s because of habitat loss and fragmentation, and hunting for the commercial luxury food trade. Remaining populations appear to be distributed in 12 areas across 17 provinces in the mountainous areas of the middle Yangtze, Yellow and Pearl Rivers. Since the 1980s, 14 nature reserves, with a total area of more than 355,000 ha, have been established for
\end{abstract}

the conservation of the Chinese giant salamander. We carried out habitat and questionnaire surveys for the species in 13 locations, and based on the results and on the little amount of published information, most of it in Chinese, we assess the current status of the species and make recommendations for its conservation management. Conservation of the Chinese giant salamander should be given a high priority and considered an important part of wetland management.

Keywords Amphibia, Andrias davidianus, China, Chinese giant salamander, decline, fragmentation.

This paper contains supplementary material that can only be found online at http://journals.cambridge.org

\section{Introduction}

The Chinese giant salamander Andrias davidianus is the largest living amphibian, reaching a maximum length of $200 \mathrm{~cm}$ and a weight of $50 \mathrm{~kg}$ (Peng et al., 1998; Zhao, 1998). It is referred to locally as wawayu (baby fish) because its call resembles a baby's cry. Historical information indicates that the species was once widely distributed in the middle and lower tributaries of the Yangtze, Yellow and Pearl Rivers, including the 18 Provinces of Anhui, Fujian, Gansu, Guangdong, Guangxi, Guizhou, Hebei, Henan, Hubei, Hunan, Jiangsu, Jiangxi, Qinghai, Shaanxi, Shanxi, Sichuan, Yunnan and Zhejiang, and the city of Chongquing (the latter has the same status as a Province) (Song, 1986; Liu, 1989; Yang, 1991; Ye et al., 1993), although Cao et al. (1999) and Zou (1995) recently confirmed that the species never occurred in Hebei and Jiangsu Provinces. The Chinese giant salamander has, however, declined sharply in both range and numbers since the 1950s because of the loss and

Xiao-ming Wang (Corresponding author), Ke-jia Zhang, Zheng-huan, You-zhong Ding and Wei Wu Department of Biology, East China Normal University, 200062, Shanghai, China. E-mail wxming@public3.sta.net.cn

Song Huang Huangshan Institute of Snakes, Huangshan 245000, Anhui, China.

Received 16 December 2001. Revision requested 31 May 2001. Accepted 9 December 2002. fragmentation of its habitat, and hunting for the luxury food market; most local populations are on the verge of extinction and some are already extinct (Anon., 1978; Zhao, 1998; Zhang \& Wang, 2000). The Chinese Government has declared the giant salamander a Class II Protected Species, which makes hunting illegal. There is relatively little information, however, on the current status of the species, and it is consequently categorized as Data Deficient on the 2003 IUCN Red List (IUCN, 2003), although it is listed as Critically Endangered in the Chinese Red Book of Amphibians and Reptiles (Zhao, 1998). In this paper we review the conservation status of the Chinese giant salamander based on recent field surveys and on the relatively small amount of published information on the species, most of it in Chinese.

\section{Methods}

We carried out questionnaire, habitat and population surveys in five provinces and in the city of Chongquing during 2000-2001 (Table 1; Fig. 1). These areas are located in the middle and lower drainage of the Yangtze River and the middle drainage of the Yellow River. In the same years we also surveyed six reserves established specifically for the Chinese giant salamander and one national reserve (Hupingshan Natural Reserve in Shimen County, Hunan Province). 
Table 1 Locations, survey dates, number of questionnaires administered, and type of survey (other than questionnaire) carried out for the Chinese giant salamander in 13 areas (numbered locations are indicated on Fig. 1).

\begin{tabular}{|c|c|c|c|c|}
\hline No. & Location & Survey date & No. questionnaires & Type of survey \\
\hline 1 & Xiuning County, Anhui Province & Jan.-Feb. 2000, Aug. 2000 & 4 & \\
\hline 2 & Qimen County, Anhui Province & Jan.-Feb. 2000, Aug. 2000 & 3 & \\
\hline 3 & Yuexi County, Anhui Province & Jan.-Feb. 2000, Aug. 2000 & 3 & \\
\hline 4 & Huoshan County, Anhui Province & Jan.-Feb. 2000, Aug. 2000 & 5 & \\
\hline 5 & Jinzha County, Anhui Province & Jan.-Feb. 2000, Aug. 2000 & 7 & \\
\hline 6 & $\begin{array}{l}\text { Shimen County, Hunan Province } \\
\text { (Hupingshan Natural Reserve) }\end{array}$ & Oct. 2000, Apr.-July 2001 & 14 & Population, habitat \\
\hline 7 & $\begin{array}{l}\text { Zhangjiajie County, Hunan Province } \\
\text { (Zhangjiajie Giant Salamander Reserve) }\end{array}$ & Oct. 2000, Apr.-July 2001 & 4 & Habitat \\
\hline 8 & $\begin{array}{l}\text { Yongshun County, Hunan Province } \\
\text { (Youshun Liangca Giant Salamander Reserve) }\end{array}$ & Oct. 2000, Apr.-July 2001 & 7 & Habitat \\
\hline 9 & $\begin{array}{l}\text { Youyang County, Chongquing city } \\
\text { (Youyang Giant Salamander Reserve) }\end{array}$ & Nov. 2000, July 2001 & 6 & Habitat \\
\hline 10 & Mabian County, Sichuan Province & July 2000 & 7 & \\
\hline 11 & $\begin{array}{l}\text { Taibai County, Shaanxi Province } \\
\text { (Taibai Giant Salamander Reserve) }\end{array}$ & July-Aug. 2001 & 4 & Habitat \\
\hline 12 & $\begin{array}{l}\text { Lushi County, Henan Province } \\
\text { (Lushi Giant Salamander Reserve) }\end{array}$ & Aug. 2001 & 5 & Habitat \\
\hline 13 & $\begin{array}{l}\text { Xin'an County, Henan Province } \\
\text { (Xin'an Giant Salamander Reserve) }\end{array}$ & Aug. 2001 & 3 & Habitat \\
\hline
\end{tabular}

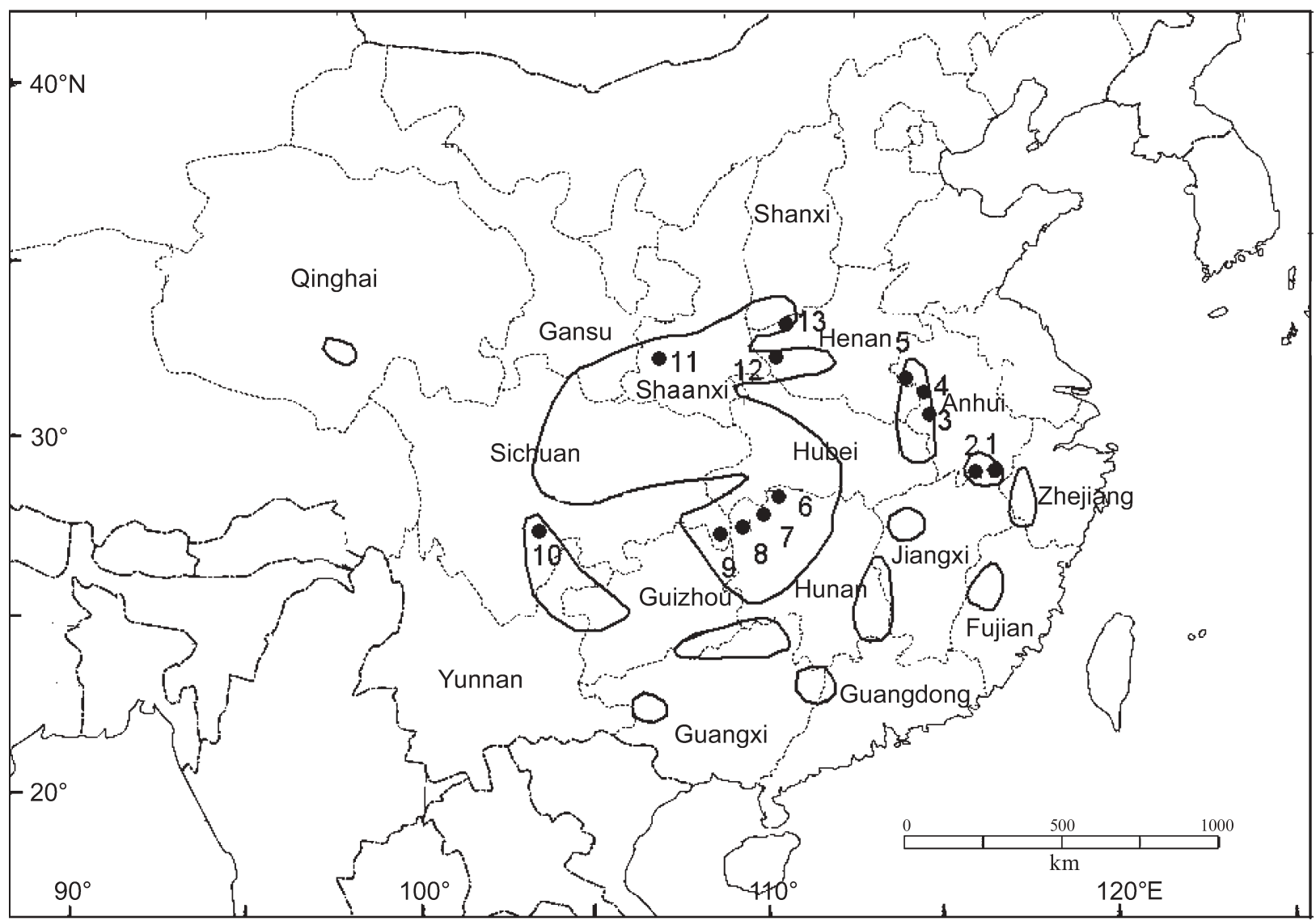

Fig.1 The current distribution of the Chinese giant salamander (heavy lines); labelled areas are Provinces. Numbered points indicate the locations of our 13 surveys (Table 1). The outlines indicating the 12 areas and regions where we believe the Chinese giant salamander still exists were drawn based on our surveys (Table 1) and from published information, most of it in Chinese. 
During the surveys we noted the number of hunters that we encountered, the number of bow-hooks (traditionally used to catch giant salamanders) found in the river, and qualitative habitat information (vegetation, slope of the bank, river bank type, water $\mathrm{pH}$ and speed, and elevation) to assess habitat quality. We made nighttime spotlight counts along riverbanks. At each of the 13 survey sites we undertook questionnaire surveys (Appendix) involving management personnel and villagers to gather information about the life history, current population status, local trade in and threats to the Chinese giant salamander.

In Hupingshan Natural Reserve we carried out a population survey for the salamander, using bow-hooks (Liu et al., 1991). The bow-hook is made of small pieces of bamboo and is fitted with 4-5 sharp hooks and is fixed at the entrance of a salamander 'den', baited with frogs or small fish. When the animal eats the bait it is captured on the hooks. The bow-hook can cause small injuries to the back of the animal but these are not serious or debilitating. Where salamanders were captured in this way, any injuries were treated with tincture of iodine to prevent any infection; no animals were killed using this method. We fixed bow-hooks at the entrances to dens in the daytime, and checked the following morning for any captures; we measured the weight, total length and width, and head and tail length of all individuals captured and then released them at the locations where they were caught. During our surveys in the Reserve in 2000 and 2001 (Table 1) we surveyed a total of 11 sites along a $9.5 \mathrm{~km}$ stretch of each of two rivers. At each site 20-35 hooks were used, depending on the local topography of the river.

\section{Results}

\section{Population survey}

Our population survey in Hupingshan Natural Reserve was unsuccessful, as we were only able to capture one salamander. During our time in the reserve, however, we saw local hunters capture six salamanders by electrofishing, and one using bow hooks. The body length of these eight captured individuals was 9.6-39.1 cm (mean $=19 \mathrm{~cm}$ ), and their weight 8-276 $\mathrm{g}$ (mean =151 g). We judged the age of these individuals to be $2-4$ years. We did not observe any salamanders during the night-time spotlight survey in the Reserve. We were told that in the Reserve $c .100$ salamanders are captured illegally every year (local hunters, pers. comm.).

During the total of 82 days that we searched for salamanders at night-time in the six other areas in which we carried out habitat surveys (Table 1), we did not observe any salamanders. This cannot be interpreted as a complete absence of salamanders at these sites but it does indicate that densities are extremely low. Results from the questionnaire surveys indicated that salamanders still occur in these areas.

A total of 72 questionnaires were completed and the consensus of opinion expressed by the respondents was that Chinese giant salamanders were abundant prior to the 1980s, when individuals could be easily found and captured, that populations have since declined and it has become difficult to capture salamanders, and that the main reasons for this decline are heavy poaching, habitat fragmentation and pollution.

\section{Current distribution}

From our surveys, enquiries and the small amount of available published information (Yichang Station of Fishery Technique, 1974; Song, 1983, 1990; Liu, 1989; Cheng, 1993, 1998; Peng et al., 1998) we produced a distribution map for the Chinese giant salamander that covers 17 Provinces (Fig. 1). The species appears to survive in 12 populations in small rivers in mountainous areas. In the lower reaches of the Yangtze River the Chinese giant salamander survives mainly in Dabie Mountain, Huangshan Mountain and Jiulong Mountain. The range also includes the upper reaches of the Yellow River: Tianshui County in Gansu Province, Lishan District in Shanxi Province, Lushi County in Henan Province and Luonan County in Shaanxi Province. The species has also been found at over 4,000 $\mathrm{m}$ in Qinghai Province in the upper reaches of the Yellow River (Anon., 1989; Wang Yuezhao, pers.comm.). On 28 July 2000 it was reported by the Xinghua News Agency that an individual salamander weighing $3.2 \mathrm{~kg}$ was captured near a water power station in the upper reaches of the Yellow River. The species is also present in the upper reaches of the Pearl River, including the Beijiang and Liujiang Rivers.

\section{Preferred habitats}

Based on our surveys and on responses to the questionnaires, the salamanders appear to inhabit clear, cool and slow- to swift-flowing mountainous streams of $\mathrm{pH}$ 6.0-7.0 that have caves in rocky banks with good forest cover, in often steep valleys at altitudes of 265-1,355 m. We identified four types of salamander habitat: (1) Creeks of relatively small size (width $<10 \mathrm{~m}$ and water depth $<1 \mathrm{~m}$ ), with a relatively slow flow, and a bed of mud that is usually covered by gravel. (2) Rivers characterized by fast-flowing water with many deep pools, and riverbanks mainly of large rocks; the deep pools in this habitat type appear to be the most favourable of the four habitat types for salamanders. (3) Rivers characterized by a few pools, a flat riverbed, relatively 
slow flowing water often $<5 \mathrm{~m}$ in depth, riverbanks mainly of rocks and gravel, and widths of 6-30 m. (4) Underground rivers with pools, within limestone caves in the mountains.

\section{Discussion}

The populations of Chinese giant salamander in the areas that we investigated are low, and in some cases probably already extinct. This is partly a result of heavy hunting pressure. The species has been heavily exploited for a long time by local people. It is known that Chinese giant salamanders have been collected since the 1960s (Song, 1982; Liu \& Liu, 1993; Gui, 1998). In three provinces for which information is available there was already a marked decline in the number of salamanders being collected from the wild by the 1970s (Table 2). Hunting often occurs within protected areas. In Yongshun Reserve in Hunan Province we saw three salamander hunting canoes containing $>150$ bow-hooks. During our survey of Hupingshan Natural Reserve we encountered three hunters and observed 17 bow-hooks.

Information obtained during our questionnaire surveys suggested that hunters go unpunished for illegal hunting. These surveys also provided information on a number of instances of poaching: (1) in 1998 several villagers spent 2 days pumping the water out of a pool in a cave to capture the salamanders within, (2) in July 2000 several hunters used pesticide to kill c. 100 Chinese giant salamander larvae in the Tuping River of Youyang County, city of Chongquing, (3) >100 kg of salamanders were until recently collected each year in Dabie Mountain in Anhui Province, (4) in August 2000, $>100$ juvenile Chinese giant salamanders were illegally transferred to two small ponds for breeding in Qimen County of Anhui Province. The value of salamander meat sustains the local black market. The price was US \$5 per $\mathrm{kg}$ in the early 1980s but is now US $\$ 100$ per $\mathrm{kg}$ or more in Guizhou Province (Gui, 1998). We found that the value is up to US $\$ 120$ per $\mathrm{kg}$ in Anhui Province and US \$150 per kg in Sichuan Province. Most of the illegal

Table 2 Declines in the quantity of Chinese giant salamanders purchased in four areas at two different points in time; data from Liu (1989), Hu (1987) and Song (1983).

\begin{tabular}{llc}
\hline Area & Year & Quantity purchased (kg) \\
\hline Sangzhi County, & 1954 & 7,500 \\
Hunan Province & 1978 & 1,000 \\
Xiangxi State, & $1960 \mathrm{~s}$ & 15,000 \\
Hunan Province & $1970 \mathrm{~s}$ & 2,750 \\
Huoshan County, & 1968 & 500 \\
Anhui Province & 1973 & 35 \\
Taibai County, & 1973 & 3,813 \\
Shaanxi Province & 1979 & 1,300 \\
\hline
\end{tabular}

collections from the wild are sold to restaurants, and we found that the price of Chinese giant alamander in a restaurant is US \$250-400 per kg in Guangdong and Hunan Provinces. Prices such as these are a strong incentive to salamander hunters and make it extremely difficult to halt the illegal capture and trade.

Chinese giant salamander habitat has been destroyed and fragmented by human activities such as deforestation, construction of dams and pollution. Electric power stations and reservoirs have often been constructed in salamander habitat. Liu (1989) noted that changes to salamander populations in 10 counties of Hunan Province, including dam construction for electric power and irrigation, drastically altered the species' riverine habitat to the point that all populations in the Province are now in danger of extinction. In early 2000 it was reported to us that chemical pollution in the upper reaches of Dadu River in Sichuan Province resulted in the death of many aquatic animals, including Chinese giant salamanders. In Mabian County, Sichuan Province, which was formerly an important habitat for the species, deforestation and damage to riverine vegetation due to the intensive farming practices has resulted in heavy siltation and destruction of habitat. The Chinese giant salamander appears to survive better in areas where farming is less intensive, perhaps due to lower levels of pesticide and fertiliser run-off.

The weights of giant salamanders being captured appears to be much lower than formerly, presumably because of increased hunting pressure. In Sangzhi County in Hunan Province three salamanders captured during the 1950s weighed $>50 \mathrm{~kg}$ and most individuals weighed c. 35-40 kg; all individuals captured in the same locality during the 1970 s were $<5 \mathrm{~kg}$ (Liu, 1989). In Dabie Mountain in Anhui Province the weight of collected animals was c. 3-4 kg during the mid-1960s, but only $0.5-1 \mathrm{~kg}$ in the early 1970s (Hu, 1987). Illegal collection of Chinese giant salamanders from the wild is still the main factor contributing to the population decline despite the legal protection provided to the species since 1988. The salamander trade takes place on a large scale over its entire range. Collecting is mainly to meet the demand for the commercial trade within China. Hunting occurs widely and in many counties has increased in recent years; hunters often capture all individuals in a stream using fishing nets and dynamiting (Zhang \& Wang, 2001). Two consignments, of 400 and 323 living salamanders each, were found by forest police at the train stations of Yueyang and Huaihua in Hunan Province, respectively in the late 1980s (Liu, 1989).

Conservation activities for the giant salamander have so far involved mostly captive breeding, with centres established in Sichuan, Hunan, Shaanxi, Guizhou, Henan and Anhui Provinces during the 1960s and 1970s. These centres have made progress in terms of being able to 
Table 3 Chinese giant salamander reserves in China with location, grade, area and year established. Data from Liu et al. (1996) and Mackinnon et al. (1998).

\begin{tabular}{|c|c|c|c|c|}
\hline Reserve & Location, Province & Grade & Area (ha) & Year established \\
\hline Lushi Giant Salamander Reserve & Lushi, Henan & Provincial & 184,350 & 1982 \\
\hline Xixia Giant Salamander Reserve & Xixia, Henan & Provincial & 131,040 & 1982 \\
\hline Qingyaoshan Giant Salamander Reserve & Xin'an, Henan & Provincial & 9,000 & 1988 \\
\hline Youyang Giant Salamander Reserve & Youyang, Chongquing city & County & 4,000 & 1989 \\
\hline Taibai Huangshuihe Giant Salamander Reserve & Taibai, Shaanxi & Provincial & 3,300 & 1986 \\
\hline Zhuxi Giant Salamander Reserve & Zhuxi, Hubei & Provincial & 800 & 1986 \\
\hline Zhongjianhe Giant Salamander Reserve & Xianfeng, Hubei & Provincial & 264 & 1994 \\
\hline Dachenshan Giant Salamander Reserve & Loudi, Hunan & County & 100 & 1987 \\
\hline Sangzhi Quanhe Giant Salamander Reserve & Sangzhi, Hunan & County & 4,810 & 1983 \\
\hline Yongshun Liangcha Giant Salamander Reserve & Yongshun, Hunan & * & 24,400 & 1988 \\
\hline Chenxi Longmen Giant Salamander Reserve & Chenxi, Hunan & County & 1,700 & 1984 \\
\hline Zhangjiajie Giant Salamander Reserve & Zhangjiajie, Hunan & National level & 12 & 1998 \\
\hline Qianxi Giant Salamander Reserve & Qianxi, Guizhou & County & 1,000 & 1986 \\
\hline Jing'an Liaohe Giant Salamander Reserve & Jing'an, Jiangxi & County & 100 & 1980 \\
\hline
\end{tabular}

*It was not possible to ascertain the status of this reserve; even the relevant government agency could not provide any information.

successfully care for young wild-caught salamanders and preventing and curing diseases in captivity, but reproduction in captivity has proved elusive (Ye et al., 1993; Peng et al., 1998). It is therefore imperative to identify a conservation strategy that will be effective for the remaining wild populations.

Since the 1980s 14 nature reserves have been established in Henan, Jiangxi, Chongquing city, Shaanxi, Guizhou and Hunan Provinces (Table 3) to protect wild Chinese giant salamander populations. In visits to six of the 14 reserves totalling 124 days we were unable to observe salamanders, and we found that there were severe problems and threats in each area (Table 4). Limited habitat, a lack of protection and insufficient funds appear to be the main problems.

Table 4 Problems and threats to the six giant salamander reserves surveyed.

\begin{tabular}{|c|c|}
\hline Reserve & Problems and threats \\
\hline Lushi Giant Salamander Reserve & $\begin{array}{l}\text { Shortage of funding and } \\
\text { personnel, poaching }\end{array}$ \\
\hline $\begin{array}{l}\text { Qingyaoshan Giant Salamander } \\
\text { Reserve }\end{array}$ & $\begin{array}{l}\text { Development of tourism, } \\
\text { construction, lack of } \\
\text { conservation action plan }\end{array}$ \\
\hline Youyang Giant Salamander Reserve & $\begin{array}{l}\text { Reserve has yet to be } \\
\text { properly established, } \\
\text { poaching }\end{array}$ \\
\hline $\begin{array}{l}\text { Taibai Huangshuihe Giant } \\
\text { Salamander Reserve }\end{array}$ & $\begin{array}{l}\text { Reserve has yet to be } \\
\text { properly established, } \\
\text { poaching }\end{array}$ \\
\hline $\begin{array}{l}\text { Yongshun Liangcha Giant } \\
\text { Salamander Reserve }\end{array}$ & $\begin{array}{l}\text { Reserve boundary not } \\
\text { delineated and funding } \\
\text { and personnel not } \\
\text { allocated, heavy } \\
\text { poaching }\end{array}$ \\
\hline $\begin{array}{l}\text { Zhangjiajie Giant Salamander } \\
\text { Reserve }\end{array}$ & $\begin{array}{l}\text { Salamander habitat not yet } \\
\text { protected }\end{array}$ \\
\hline
\end{tabular}

The results of our surveys indicate that wild populations of the Chinese giant salamander are on the verge of extinction and that this endemic species will become extinct in China if no new conservation actions are taken in the near future. Based on our work we make three main recommendations for the development of a management programme for the species.

Firstly, further surveys need to be carried out throughout the species' range to establish its conservation status and demography, and to obtain a better understanding of its life history. Standard protocols for long-term monitoring of wild populations need to be implemented. In addition, it is important to identify the specific risks to populations in the various areas where it still survives. The genetic identities of populations should also be investigated, as research on eight populations (Murphy et al., 2000) has indicated that there are regional genetic differences and that confiscated salamanders should be released in their original rivers. Research should be organized and supported by the administrators of wildlife protection, such as the Forestry Bureau, but carried out by conservation biologists.

Secondly, there needs to be proper protection of Chinese giant salamander habitat, especially nesting sites, along with prevention of pollution from run-off, the banning of poisoning and dynamiting as fishing methods, and a review of irrigation works within nature reserves. Enforcement of existing laws that prohibit the illegal collection and transportation of animals should become a priority. All these actions require the cooperation of the agricultural sector, irrigation works, police, the Forestry Bureau, local government and the community.

Thirdly, a public information campaign to better educate local inhabitants as to the status and plight of this important endemic species should be developed, and implemented as part of a management plan. 


\section{Acknowledgements}

This work would not have been possible without financial support from the Wildlife Conservation Society, Denver Zoological Foundation, and the Tenth 5-year '211 Project'. We thank Drs George Schaller, John Thorbjarnarson and Richard Reading for organizing the funds and for encouragement. We wish to thank all the individuals who took part in our surveys, especially Chen Jiaxing, Director of Hupingshan fishery station, Qing Jigang of Hupingshan fishery station, Liao Xiansheng, Vice-Director of Hupingshan National Reserve, Xiang Xuxia of Youshun county and Li Jun, Director of the Fishery Department of Youyang county. Many thanks to Dr. Roger Rosscoe for his help in revising the manuscript for publication. We thank Prof. Endi Zhang for suggestions on the first version of the manuscript and Dr Wenshan He for drawing the map. An anonymous reviewer and Prof. Yuezhao Wang are thanked for providing valuable comments.

\section{References}

Anon. (1978) The Economic Amphibians and Reptiles of China. Shanghai Science and Technology Press, Shanghai, China. [in Chinese]

Anon. (1989) The Economic Fauna of Qinghai. Qinghai People Publishing House, Xining, China. [in Chinese]

Cao, Y.-P., Xia, Q.-Y., Li, J., Xie, S., Cui, J.-T. \& Liu, Q.-P. (1999) Probable absence of natural populations of Andrias davidianus in Hebei Province, including Beijing and Tianjing. Sichuan Journal of Zoology, 18, 109-110. [in Chinese]

Cheng, W.-F. (1993) Research into the ecology and behaviour of the giant salamander and conservation of resources. In Proceedings of the First Asian Herpetological Meeting (ed. Zhao Ermi), pp. 296-300. Huangshan, China. [in Chinese]

Cheng, W.-F. (1998) Ecological and behavioral research of Andrias davidianus and its protection. Russian Journal of Herpetology, 5, 2-4.

Gui, Q.-P. (1998) The Chinese giant salamander and its conservation in Tongren district of Guizhou Province. Journal of Chinese Wildlife, 19, 10-11. [in Chinese]

Hu, X-L. (1987) The preliminary study of the Chinese giant salamander in Dabian Mountain of Anhui province. Journal of the Anhui Normal University, 1, 69-73. [in Chinese]

IUCN (2003) 2003 IUCN Red List of Threatened Species. IUCN, Gland, Switzerland [http:/ / www.redlist.org, accessed 21 November 2003].

Liu, D.-L., Wu, Z.-L., Yang, H.-X., Cheng, C.-D., Zhao, X.-Y., Wang, X.-L., Wang, M.-H. \& Wang, J.-M. (eds) (1996) Nature Reserves in China. Shanghai Education Publishing House of Science \& Technology, Shanghai, China.

Liu G.-J. (1989) A rare and precious animal in China - the giant salamander. Chinese Journal of Zoology, 24, 43-45. [in Chinese]

Liu, G.-J. \& Liu, Q.-P. (1993) The biology and conservation of the Chinese salamander. In Proceedings of the First Asian Herpetological Meeting (ed. Zhao Ermi), pp. 293-295.

Huangshan, China. [in Chinese]
Liu, S.-F.,Yang, X-Z \& Tian, Y.-X. (1991) A counting method for Chinese giant salamanders in Xushui River. Chinese Journal of Zoology, 26, 35-40. [in Chinese]

Mackinnon J., Men, S., Zhang, P.-S., Jia, Z.-H., Zhu, X. \& Mei, W.-Y. (eds) (1998) Summary of Conservation of Biodiversity in China. China Forestry Publishing House, Beijing, China. [in Chinese]

Murphy, R.W., Fu, J.Z., Upton, D.E., De Lema, T. \& Zhao, E. M. (2000) Genetic variability among endangered Chinese giant salamander, Andrias davidianus. Molecular Ecology, 9, 1539-1547.

Peng, K.-M., Fen, R.-P. \& Cheng, X.-P. (1998) The Chinese giant salamander. Journal of Chinese Wildlife, 19, 11. [in Chinese]

Song, M.-T. (1982) The habitat of giant salamanders in Shannxi Province. Chinese Journal of Zoology, 6, 11-13. [in Chinese]

Song, M.-T. (1983) The population composition of giant salamanders in Shangnan district of Shannxi Province. Chinese Journal of Ecology, 4, 41-42. [in Chinese]

Song, M.-T. (1986) Ecology and distribution of Chinese giant salamanders. La Animala Mondo, 3(1), 75-77. [in Chinese]

Song, M.-T. (1990) Analysis of the diet of giant salamanders (Andrias davidianus). Journal of Zoological Research, 3, 192. [in Chinese]

Yang, D.-T. (ed.) (1991) The Amphibian Fauna of Yunnan. China Forestry Publishing House, Beijing, China. [in Chinese]

Ye, C.-A., Fei, L. \& Hu, S.-Q. (eds) (1993) Rare and Economic Amphibians of China. Sichuan Publishing House of Science \& Technology, Chengdu, China. [in Chinese]

Yichang Station of Fishery Technique (1974) Research report on the giant salamander. Freshwater Fisheries, 43, 14-16. [in Chinese]

Zhang, K.-J. \& Wang, X.-M. (2000) Status of conservation biology of Chinese giant salamander. In The Proceedings of the Fourth Asian Herpetological Conference, p. 172. Chengdu, China.

Zhang, K.-J.\& Wang, X.-M. ( 2001) Chinese giant salamander. Forest and Mankind, 2001(3), 43-45. [in Chinese]

Zhao, E.-M. (1998) China Red Data Book of Endangered Animals: Amphibia and Reptilia. Science Press, Beijing, China. [in Chinese with English summary]

Zou S. C. (1995) The floristics and geographical regionalization of the amphibians of Jiangshu Province (including Shanghai). Research Book of Snakes and Frogs, 8, 83-86. [in Chinese]

\section{Appendix}

The Appendix for this article is available online at http:/ /journals.cambridge.org

\section{Biographical sketches}

Xiao-ming Wang's research interest is in the conservation of threatened wildlife in China. Ke-jia Zhang studies wetlands and conservation on the Tibetan plateau. Zheng-huan Wang studies the population ecology of reptiles, amphibians and other endangered wildlife. You-zhong Ding is currently completing research on the status and population ecology of the Chinese alligator and has conducted studies on the effect of heavy metals on wildlife. Wei Wu's main research interest is in primate behavioural ecology. Song Huang carries out research on breeding snakes in captivity. 